\title{
O IMPACTO DOS RESULTADOS DO SARESP NA AÇÃO DOCENTE NOS ANOS INICIAIS DO ENSINO FUNDAMENTAL
}

\author{
THE IMPACT OF SARESP RESULTS ON TEACHING ACTION \\ IN ELEMENTARY SCHOOL EARLY YEARS
}

\section{EL IMPACTO DE LOS RESULTADOS DEL SARESP EN LA ACCIÓN DOCENTE EN LOS AÑOS INICIALES DE LA ENSEÑANZA PRIMARIA}

\author{
Karina Machado ${ }^{1}$ \\ Maria Iolanda Monteiro ${ }^{2}$
}

\begin{abstract}
RESUMO
Este texto apresenta alguns dados construídos e discutidos durante a pesquisa de mestrado (2015 2017), sobre os impactos dos resultados do Sistema de Avaliação do Rendimento Escolar do Estado de São Paulo (SARESP) nas ações pedagógicas dos docentes de uma das unidades escolares na rede de ensino Serviço Social da Indústria (SESI - SP). A partir da análise dos resultados desta avaliação externa, nas edições de 2013 e 2014, no componente de Língua Portuguesa do $2^{\circ}$ ano do ensino fundamental, observamos mudanças significativas nos índices de desempenho dos alunos do SESI. A pesquisa, pautada na metodologia qualitativa, contou com a colaboração de um grupo de cinco docentes, dos anos iniciais do ensino fundamental, que, por meio de uma entrevista semiestruturada e de um questionário, compartilharam informações que contribuíram para a análise dos dados. Neste artigo, perpassaremos pelas dimensões da avaliação escolar, com especial atenção à avaliação de sistemas. Apresentaremos uma breve explanação da concepção e da metodologia do ensino da Língua Materna, na rede SESI. E, no que se refere ao SARESP, optamos por dar voz às professoras. Transcrevemos fragmentos das entrevistas que demonstram o entendimento sobre a aplicabilidade desta avaliação. A análise dos resultados, para e com a equipe, resultou na prática do uso de simulados, para treino dos alunos.
\end{abstract}

Palavras-chave: Avaliação. SARESP. Língua Materna. Rede SESI.

\begin{abstract}
This text presents some data constructed and discussed during the master's research (2015-2017) about the impact of results in the Evaluation System of Academic Achievement of São Paulo State (SARESP) on teachers' pedagogical actions in one of the educational units of Industry Social Service (SESI - SP). From the analysis of results of this external evaluation, in 2013 and 2014 editions in Portuguese Language component of elementary school 2nd grade, we observed significant changes in the performance indexes of SESI students. The research, based on the qualitative methodology, with a group of five teachers from elementary school early years, who collaborated through a semi-structured interview and a questionnaire, shared information that contributed to the data analysis. In this article we will go through the school assessment dimensions, with particular attention to the evaluation systems, we will present a brief explanation of the conception and methodology of Native Language teaching in SESI system and, as regard to SARESP, we decided to hear the teachers. We transcribed fragments of the interviews demonstrating the understanding about the applicability of this evaluation. The analysis of results, for and with the team, resulted in the practice of using simulations for training students.
\end{abstract}

Keywords: Evaluation. SARESP. Native Language. SESI System

\section{RESUMEN}

Este texto presenta algunos datos construidos y discutidos durante la investigación de maestría (2015 2017), sobre los impactos de los resultados del Sistema de evaluación del rendimiento Escolar del Estado

\footnotetext{
1 Universidade Federal de São Carlos (UFSCar). São Carlos - SP, Brasil. ORCID: http://orcid.org/0000-0003-3701-031X. E-mail: profkarinam@ gmail.com.

2 Universidade Federal de São Carlos (UFSCar). São Carlos - SP, Brasil. ORCID: http://orcid.org/0000-0002-4534-1437. E-mail: mimonteiro@ ufscar.br.
}

Artigo recebido em março de 2018. Aprovado em agosto de 2019. 
de São Paulo (SARESP) en las acciones pedagógicas en una de las unidades escolares de la red de enseñanza del Servicio Social de la Industria (SESI - SP). A partir del análisis de los resultados de esta evaluación externa, en las ediciones de 2013 y 2014 en el componente de Lengua Portuguesa del $2^{\circ}$ año primario, observamos cambios significativos en los índices de desempeño de los alumnos del SESI. La investigación, basada en la metodología cualitativa, contó con la colaboración de un grupo de cinco docentes de los años iniciales de la enseñanza primaria, que, por medio de una entrevista semiestructurada y de un cuestionario, compartieron informaciones que contribuyeron para el análisis de los datos. En este artículo atravesaremos por las dimensiones de la evaluación escolar, con especial atención a la evaluación de sistemas, presentaremos una breve explicación de la concepción y de la de enseñanza de la Lengua Materna en la red SESI y, lo que se refiere al SARESP, optamos por dar voz a las profesoras. Transcribiremos fragmentos de las entrevistas que demuestran el entendimiento sobre la aplicabilidad de esta evaluación. El análisis de los resultados para y con su la equipe, resultó en la práctica del uso de simulados, para el preparo de los alumnos.

Palabras-clave: Evaluación. SARESP. Lengua materna. Red SESI.

\section{INTRODUÇÃO}

A avaliação escolar é organizada em diferentes dimensões que dialogam e trazem subsídios para a reflexão do processo avaliativo e da aprendizagem dos alunos. Uma das dimensões discute a avaliação em larga escala, também chamada de avaliação de sistemas, a qual tem sido instrumento norteador da qualidade da educação em âmbito nacional e estadual. É esta dimensão que alicerçou o caminho percorrido na pesquisa ${ }^{3}$ apresentada neste texto.

Neste presente registro, apresentamos as diferentes dimensões da avaliação escolar, com ênfase na avaliação em larga escala, realizada pela Secretaria de Estado da Educação - o Sistema de Avaliação do Rendimento Escolar do Estado de São Paulo (SARESP). Este instrumento tem por objetivo diagnosticar o desempenho dos alunos matriculados na rede estadual, a partir da realização de uma prova organizada e pautada nas bases conceituais do currículo do Estado de São Paulo ${ }^{4}$. Esta avaliação, apesar de organizada para este público, poderá ser aplicada em outras instâncias escolares, por meio de adesão. "O Serviço Social da Indústria (SESI) é uma entidade de direito privado, estruturada em base federativa" (SESI, 2015, p. 10) e participa desta avaliação por meio de adesão.

Esta rede particular de ensino possui material didático próprio, elaborado entre os anos de 2009 e 2013, organizado em três volumes: o livro do aluno, o livro de textos e o livro do professor. Este último contém as orientações pedagógicas direcionadas ao docente para o desenvolvimento das unidades de trabalho e suas respectivas atividades, de cada um dos componentes curriculares. Porém, como instrumento padronizado de verificação do desempenho dos alunos, adere ao SARESP.

Ao analisar os resultados, da rede particular, nas edições de 2013 e 2014, no $2^{\circ}$ ano do ensino fundamental, no componente de Língua Portuguesa, notamos uma mudança significativa. Também foi analisado o desempenho individual das unidades escolares e, dentre elas, selecionamos uma em que o resultado apresentou uma queda significativa no nível de desempenho avançado. Nesta unidade, na primeira edição, em que os alunos do $2^{\circ}$ ano participaram, $68,8 \%$ foram classificados no nível de desempenho avançado e, no ano seguinte, este índice reduziu para 9,7\%. Tal mudança gerou questionamentos sobre o que estes resultados estavam indicando.

Pautada na metodologia qualitativa, buscamos a literatura relacionada à avaliação escolar; analisamos os documentos elaborados pela Secretaria de Estado da Educação (SEE) referentes ao SARESP, o material didático da rede SESI - SP do $1^{\circ}$ ao $5^{\circ}$ ano

\footnotetext{
Pesquisa intitulada "O Sistema de Avaliação do Rendimento Escolar do Estado de São Paulo (SARESP) e o ensino da Língua Materna em uma rede particular", vinculada ao Programa de Pós - Graduação em Educação da Universidade Federal de São Carlos; aprovada pelo comitê de ética a partir do parecer consubstanciado n $\mathrm{n}^{0} 1.631 .719$.

4 Além da prova realizada pelos estudantes, o SARESP inclui também dois tipos de questionários: um realizado pela gestão, com o objetivo de analisar os fatores associados à aprendizagem e o outro, direcionado aos alunos, com o objetivo de coletar informações sobre o contexto social, econômico, cultural e familiar destes (SÃO PAULO, 2014b).
} 
do ensino fundamental. Contamos, ainda, com a colaboração de cinco docentes da unidade escolar, as quais responderam a um questionário e também cederam uma entrevista organizada num roteiro semiestruturado.

Nesta entrevista, especificamente no eixo destinado à avaliação, elencamos algumas questões que nos ajudariam a conhecer o entendimento destas profissionais quanto: à prática da avaliação formativa, à compreensão das docentes em relação à aplicação do SARESP na rede particular e, ao uso dos resultados desta avaliação em seu planejamento de aulas.

Realizamos a leitura dos relatórios desta avaliação em larga escala e verificamos que, além do instrumento aferir habilidades básicas a serem desenvolvidas pelos alunos em cada ano escolar, elas se repetiram nas edições analisadas. Outra etapa da pesquisa concretizou-se com a necessidade de conhecer a metodologia do ensino da língua materna na rede SESI, para que pudéssemos conhecer o desenvolvimento do trabalho, isto é, o que está sendo oferecido ao aluno e, posteriormente, o que está sendo aferido no teste padronizado.

Enfim, para que pudéssemos alcançar o objetivo de compreender a contribuição (ou não) do uso dos indicadores da avaliação em larga escala do estado de São Paulo, para o planejamento dos professores na rede particular citada, percorremos os caminhos apresentados anteriormente e, no desenvolvimento deste texto, compartilharemos cada etapa aqui exposta.

A avaliação externa é uma das dimensões da avaliação escolar e, muitas vezes, torna-se a vilã do desenvolvimento do trabalho do professor, pois, em algumas realidades é utilizada como critério de classificação das escolas, gerando o ranking ou, até mesmo, competitividade entre os docentes dentro da mesma unidade escolar, fato que a faz perder de vista seu objetivo principal: oferecer indicativos da qualidade de ensino.

Quando compreendemos a avaliação como mecanismo subsidiário da condução da ação docente, a qual trará material para verificar as dificuldades dos educandos e, a partir delas, trabalhar para sua aprendizagem (LUCKESI, 2008), consideramos que todas as dimensões da avaliação convirjam para tal objetivo. Especificamente no caso da avaliação em larga escala, foco deste texto, é preciso compreender que ela seja mais um instrumento de demonstração do processo de aprendizagem dos alunos e não deve assumir um caráter punitivo para os docentes nem para os discentes.

Este caráter punitivo ficou implícito durante a realização das entrevistas em nossa pesquisa, no momento em que as docentes relataram a forma como os resultados eram apresentados para toda a equipe. Em alguns momentos, os professores que alcançaram bons resultados eram chamados para compartilharem suas ações, tal fato nos indica duas situações: os resultados desta avaliação são valorizados e promovem mudanças nas práticas pedagógicas e, os docentes sentem-se responsabilizados pelos resultados dos testes padronizados.

Para as devidas reflexões que o tema nos traz, organizamos as informações consideradas relevantes sobre o papel da avaliação na prática docente nos subitens que seguem. Perpassamos pelos conceitos das dimensões e função da avaliação no cenário educacional brasileiro; posteriormente, direcionamos o olhar para a experiência avaliativa do Estado de São Paulo, presente não apenas nas escolas públicas, mas nas particulares que aderem à sua participação.

Como nosso foco foi a análise de resultados do $2^{\circ}$ ano do ensino fundamental, no componente de Língua Portuguesa, em uma escola da rede particular, discorremos sobre as habilidades aferidas neste componente curricular e comparamos com as habilidades e metas do $1^{\circ}$ ao $3^{\circ}$ ano, da rede SESI - SP, para que pudéssemos identificar as semelhanças e diferenças das habilidades desenvolvidas e aferidas, as quais poderiam culminar nos resultados da avaliação externa. Por fim, trouxemos a voz 
das docentes ${ }^{5}$ no que se refere ao uso dos resultados do SARESP em suas práticas pedagógicas.

\section{A AVALIAÇÃO NO CENÁRIO EDUCACIONAL}

Ao se discutir a dinâmica do trabalho docente, nos deparamos com diversos elementos que o compõem: conteúdos, objetivos de ensino, planejamento, plano de aula, estratégias, métodos de ensino e, entre eles, a avaliação. $O$ ato de avaliar no âmbito escolar se apresenta em diferentes momentos que, apesar de serem distintos, estão conectados: há momentos em que a escola é quem avalia, mas, há momentos em que os papéis invertem, e a escola é avaliada.

A avaliação "é uma tarefa didática necessária e permanente do trabalho docente que deve acompanhar passo a passo o processo de ensino e aprendizagem" (LIBÂNEO, 2013, p. 216), portanto, é primordial na organização do trabalho pedagógico, pois é ela quem orienta as tomadas de decisões ao longo do processo de aprendizagem dos alunos. Desta forma, avaliar é muito além de menções e notas, pois este ato, quando realizado com o objetivo de verificar o movimento do processo de aprendizagem, traz subsídios ao professor para que faça os ajustes necessários ao longo do seu planejamento. Luckesi (2011, p. 419) enfatiza que o ato avaliativo só terá sentido se subsidiar as decisões para a melhoria do desempenho dos estudantes, caso contrário "não vale a pena avaliá-lo do ponto de vista do acompanhamento".

No cenário escolar a avaliação é organizada em três grandes dimensões que se conversam e se entrelaçam na prática pedagógica. São elas: avaliação da aprendizagem, avaliação institucional e avaliação em larga escala.

Em uma sala de aula, o professor realiza suas avaliações em diversos momentos e poderá lançar mão do uso dos diferentes tipos de avaliação da aprendizagem: a classificatória, a diagnóstica e a formativa. Estes três tipos que compõem a avaliação da aprendizagem, também chamada de "avaliação de sala de aula" (SOUSA, 2000, p. 102), trazem recursos ao professor durante o processo de ensino e aprendizagem, pois permitem o acompanhamento, monitoramento e as tomadas de decisões ao longo deste processo.

O trabalho diário do professor é imbricado da necessidade de se conhecer o que o aluno já aprendeu e o que ainda precisa ser ensinado. É ao encontro desta característica, do trabalho docente, que a avaliação da aprendizagem assume o seu papel de norteadora do(s) caminho(s) a ser(em) seguido(s). Para isso, o professor deverá constantemente acompanhar a aprendizagem dos alunos. Neste acompanhamento, utilizará os três tipos de avaliação da aprendizagem citadas anteriormente.

Aavaliação diagnóstica tem como característica a identificação das potencialidades, das dificuldades e dos conhecimentos que os alunos já possuem. Ao contrário do que muitos possam imaginar, em função da interpretação do termo diagnóstico, não deverá acontecer unicamente no início de um determinado período de aprendizagem. Este diagnóstico inicial é de extrema importância para a organização das ações docentes, pois, ao identificar os conhecimentos e construções que os alunos já possuem sobre um determinado assunto, o docente realizará o seu planejamento pautado no conhecimento de seus alunos e tenderá a fazer escolhas que contribuam para o avanço do grupo. Sendo assim, a avaliação diagnóstica deverá acontecer durante todo o processo educativo, a fim de que possa alimentar constantemente as ações pedagógicas a serem escolhidas e utilizadas.

Já "a avaliação formativa é aquela que faz uso da função diagnóstica com vistas a intervenções seguras, promovendo avanços significativos” (LIMA, 2013, p. 57). Então, o docente deverá ter uma postura de constante acompanhamento do desenvolvimento do aluno. Villas Boas (2012) nos apresenta uma face da avaliação escolar denominada como avaliação informal. Esta avaliação é baseada na interação entre professor

\footnotetext{
5 As docentes estão representadas por letras (A, B, C, D, E) para preservação da identidade.
} 
e alunos. São os momentos em que o docente acompanha uma atividade, observa, interage e avalia sem prever este momento, sem aplicar menções ou comunicar ao estudante sobre $o$ ato avaliativo.

Esta postura de acompanhamento terá um papel importante para a concretização da avaliação formativa, pois é o "olhar" avaliativo do professor, tendo como parâmetros o ponto de partida do aluno, o objetivo a ser alcançado e o momento em que ele (o discente) se encontra nesta caminhada.

Outra perspectiva da avaliação formativa é o uso de diversos instrumentos avaliativos como forma de verificar, de diferentes formas, o aprendizado dos alunos. Para a elaboração destes instrumentos, o docente deverá atentar-se para a articulação dos objetivos de ensino, das estratégias utilizadas em sala de aula, para a clareza dos enunciados e também "explorar habilidades de análise, inferência, e não apenas o uso da memória para recordar dados" (LIMA, 2013, p. 56). Após a realização destas provas, o docente deverá utilizar os erros cometidos como fonte de reflexão e discussão com os discentes, além de reorganizar a sua prática, se assim for necessário. Weisz (2009) nos indica que devemos olhar o erro da criança tentando compreender o que foi que ela tentou fazer, para então, descobrirmos a natureza de seu erro e, assim, podermos auxiliá-la.

Todavia, para que o uso dos instrumentos avaliativos se caracterize na perspectiva formativa, é necessária uma diferenciação da postura e do olhar avaliativo docente, para que não seja apenas uma diversidade de instrumentos, que se encerram com uma diversidade de notas. $O$ ato de avaliar deverá trazer subsídios para verificação do andamento do processo de ensino e aprendizagem, ou, como diria Lima (2013, p. 62), "avaliar para intervir e para levar a aprender fará a diferença", isto é, tudo dependerá de como o professor conduzirá esses momentos avaliativos e o que fará com tais resultados.

Por fim, temos o terceiro tipo de avaliação da aprendizagem, a qual "é utilizada com o propósito de atribuir ao aluno uma nota ou conceito final para fins de promoção" (HAYDT, 2011, p. 220). Este tipo de avaliação, que tem como objetivo mensurar o conhecimento do aluno, é conhecida como avaliação classificatória ou somativa. É o momento escolhido para evidenciar a presença, ou a ausência, de conhecimentos trabalhados em um determinado período (semestre, bimestre, mês, ciclo etc.). Mais uma vez, chamamos a atenção para o cuidado que o docente deverá ter no uso deste tipo de avaliação, para que ela não adquira um papel excludente.

É preciso que o docente tenha constantemente a consciência de que seu grupo é heterogêneo e que tal mensuração, neste momento do processo avaliativo, não deverá caracterizar-se na comparação entre os discentes e, sim, o quanto cada um adquiriu neste tempo de aprendizagem. A utilização de critérios iguais para todos e a mensuração do conhecimento são características importantes neste momento, mas não se pode perder o olhar para o ponto de partida de cada aluno. É preciso ter o foco no objetivo a ser alcançado e na garantia da equidade da educação, sem desconsiderar a heterogeneidade do grupo discente.

Voltemos, então, à apresentação das dimensões da avaliação escolar. Até o presente momento, apresentamos a dimensão nomeada como avaliação da aprendizagem e seus três tipos: a classificatória, a diagnóstica e a formativa. As outras dimensões da avaliação escolar são: a avaliação de sistemas, também chamada de avaliação em larga escala, e a avaliação institucional.

A avaliação em larga escala é o processo de avaliação do rendimento escolar, realizado por meio de testes padronizados, com o objetivo de quantificar o desempenho da aprendizagem dos alunos e definir melhorias na qualidade de ensino. Esta avaliação está prevista na Lei de Diretrizes e Bases da Educação Nacional n. ${ }^{\circ}$ 9394/96 (BRAŠIL, 1996), em seu artigo $9^{\circ}$, inciso VI, e pode ser organizada e realizada em nível municipal, estadual e nacional. 
Ao final dos anos 80 , as escolas do nordeste, que foram financiadas com recursos do Banco Mundial no Projeto Edurural, passaram pela primeira experiência de uma avaliação que tinha por objetivo acompanhar o desempenho dos alunos (HORTA NETO, 2007). A partir desta experiência, em 1988, o Ministério da Educação (MEC) cria mecanismos de avaliação da educação para serem aplicados em todo o Brasil, surgindo assim o "Sistema de Avaliação do Ensino Público de $1^{\circ}$ grau - SAEP6" e faz o primeiro teste piloto nos estados do Paraná e Rio Grande do Norte (BONAMINO; SOUZA, 2012).

No ano de 1990, acontece a primeira avaliação em nível nacional, com amostras de escolas públicas e estudantes das $1^{a}, 3^{a}, 5^{a}$ e $7^{a}$ séries do ensino fundamental nos componentes de Língua Portuguesa, Matemática e Ciências. As $5^{\mathrm{a}}$ e $7^{\mathrm{a}}$ séries também foram avaliadas em redação (INEP ${ }^{7}$, s/d). Com os bons resultados obtidos na primeira avaliação em larga escala, o MEC define a aplicação desta a cada dois anos - periodicidade que acontece ininterruptamente desde o ano de 1993 (HORTA NETO, 2007).

A portaria $n^{\circ} 1795 / 94$ institucionaliza o SAEB como um processo nacional de avaliação que permite a todos os envolvidos (pais, alunos, gestores, professores), conhecerem e avaliarem o processo de aprendizagem dos alunos. Com a promulgação da Lei de Diretrizes e Bases da Educação Nacional n 9394/96 de 20 de dezembro de 1996 (BRASIL, 1996), a incumbência de coleta, análise e disseminação de informações sobre a qualidade educacional é atribuída à União (HORTA NETO, 2007).

Em 1997, foram desenvolvidas as Matrizes de Referência ${ }^{8}$ com a descrição das competências e habilidades que os alunos deveriam dominar em cada série avaliada, permitindo uma maior precisão técnica, tanto na construção dos itens do teste quanto na análise dos resultados da avaliação (BRASIL, 2011).

Em 2005, pela Portaria Ministerial n 931, de 21 de março de 2005, o SAEB dividiuse em dois processos de avaliação: ANEB (Avaliação Nacional da Educação Básica) e ANRESC (Avaliação Nacional do Rendimento Escolar/Prova Brasil), ambas com o objetivo de verificar a qualidade da educação brasileira. As médias de desempenho nestas duas avaliações compõem o cálculo do Ideb - Índice de Desenvolvimento da Educação Básica, criado em 2007, que define as ações e os recursos técnicos e financeiros para as áreas prioritárias da educação.

Em outra Portaria, a de n. ${ }^{\circ} 482$ de 7 de junho de 2013, surge mais uma avaliação, a ANA (Avaliação Nacional da Alfabetização), revista no Pacto Nacional pela Alfabetização na Idade Certa - PNAIC e passa a compor também o SAEB (BRASIL, 2013). Além destas três avaliações que compõem o SAEB, há, ainda, a Provinha Brasil ${ }^{9}$, que tem por objetivo diagnosticar o nível de alfabetização dos alunos que estão no $2^{\circ}$ ano do ensino fundamental, em dois momentos distintos: no início e no final do ano letivo (BRASIL, 2011). Então, atualmente o SAEB é composto por três avaliações de larga escala, como demonstra o quadro a seguir.

Quadro 1 - Demonstrativo das avaliações brasileiras em larga escala que compõem o SAEB

\begin{tabular}{|c|c|c|c|}
\cline { 2 - 4 } \multicolumn{1}{c|}{} & $\begin{array}{c}\text { Avaliação Nacional da Educação } \\
\text { Básica -Aneb }\end{array}$ & $\begin{array}{c}\text { Avaliação Nacional do } \\
\text { Rendimento Escolar - Anresc } \\
\text { (ou Prova Brasil) }\end{array}$ & $\begin{array}{c}\text { Avaliação Nacional da } \\
\text { Alfabetização -ANA }\end{array}$ \\
\hline Tipo & Amostral & Censitária & Censitária \\
\hline Público & $\begin{array}{l}\text { Estudantes matriculados na } 4^{\mathrm{a}} \\
\text { série } / 5^{\circ} \text { ano e } 8^{\mathrm{a}} \text { série/ } / 9^{\circ} \text { ano do } \\
\text { Ensino Fundamental e no } 3^{\circ} \text { ano } \\
\text { do Ensino Médio. }\end{array}$ & $\begin{array}{l}\text { Estudantes matriculados na na } \\
4^{\mathrm{a}} \text { série } / 5^{\circ} \text { ano e } 8^{\mathrm{a}} \text { série/9 } / 9^{\circ} \text { ano } \\
\text { do Ensino Fundamental. }\end{array}$ & $\begin{array}{l}\text { Estudantes do } 3^{\circ} \text { ano do Ensino } \\
\text { Fundamental. }\end{array}$ \\
\hline Tipo de instituição & Rede pública e privada & Rede pública & Rede pública \\
\hline
\end{tabular}

\footnotetext{
6 Esta nomenclatura passa a ser SAEB - Sistema de Avaliação da Educação Básica no ano de 1991 e passa a ser coordenado pelo INEP Instituto Nacional de Estudos e Pesquisas Educacionais Anísio Teixeira.

7 Disponível em: <http://portal.inep.gov.br/web/saeb/historico>. Acesso em: 05 set. 2015.

8 Para a elaboração dessas matrizes foi realizada uma consulta nacional sobre os currículos que estavam sendo praticados nas escolas, aos professores, especialistas e pesquisadores (BRASIL, 2011). Em 2001, as matrizes foram atualizadas em função da propagação dos Parâmetros Curriculares Nacionais, lançados em 1997 (HORTA NETO, 2007).

9 Esta avaliação não compõe o IDEB.
} 


\begin{tabular}{|c|c|c|c|}
\hline Periodicidade & Bianual & Bianual & Anual \\
\hline Objetivo & $\begin{array}{l}\text { Avaliar a qualidade, equidade e a } \\
\text { eficiência da educação brasileira. }\end{array}$ & $\begin{array}{l}\text { Avaliar a qualidade do ensino } \\
\text { ministrado nas escolas públicas. }\end{array}$ & $\begin{array}{l}\text { Avaliar o nível de alfabetização e } \\
\text { letramento. }\end{array}$ \\
\hline $\begin{array}{c}\text { Planejamento e } \\
\text { operacionalização }\end{array}$ & INEP & INEP & INEP \\
\hline
\end{tabular}

Fonte: INEP (s/d)

A outra dimensão da avaliação escolar é a avaliação institucional, que se caracteriza pelo momento em que a equipe realiza uma autoavaliação do trabalho realizado por todos no âmbito escolar. Segundo Depresbiteris e Tavares (2009, p. 37), é o momento em que o grupo analisa "todos os componentes do processo educacional: currículos, desempenho de professores, materiais didáticos, infraestrutura, recursos econômicos e cursos de formação, entre outros".

Neste momento de avaliação, também podem ser utilizados os resultados das avaliações de aprendizagem e de larga escala, como indicadores do nível em que se encontram em relação às metas propostas pela equipe, em seu projeto pedagógico. Como dissemos, estas três dimensões estão conectadas, se entrelaçam, e, quando utilizadas nesta perspectiva de diálogo entre elas, tendem a contribuir na equidade da qualidade educacional.

\section{A EXPERIÊNCIA AVALIATIVA DO ESTADO DE SÃO PAULO}

Em 1996, a Secretaria de Estado da Educação, por meio da resolução $n^{\circ} 27$, implementa o Sistema de Avaliação do Rendimento Escolar do Estado de São Paulo - SARESP, com o intuito de diagnosticar o desempenho dos alunos e das escolas estaduais. Os resultados deste diagnóstico subsidiariam o trabalho docente, pois revelariam as habilidades desenvolvidas e as habilidades deficitárias, proporcionando a escolha de estratégias adequadas para o desenvolvimento do trabalho pedagógico. Tal intenção de diagnóstico é claramente explicitada na referida Resolução, no inciso II do $1^{\circ}$ artigo:

II - verificar o desempenho dos alunos nas séries do ensino fundamental e médio, bem como nos diferentes componentes curriculares, de modo a fornecer ao sistema de ensino, às equipes técnico-pedagógicas das Delegacias de Ensino e às Unidades Escolares informações que subsidiem:

a) a capacitação dos recursos humanos do magistério;

b) a reorientação da proposta pedagógica desses níveis de ensino, de modo a aprimorá-la;

c) a viabilização da articulação dos resultados da avaliação com o planejamento escolar, a capacitação e o estabelecimento de metas para o projeto de cada escola, em especial a correção do fluxo escolar. (SÃO PAULO, 1996).

Esta avaliação em larga escala utiliza procedimentos metodológicos formais e científicos na coleta e sistematização das informações e permite a comparação dos resultados de aprendizagem ano a ano. Além da prova realizada pelos estudantes, o diagnóstico é complementado com dois tipos de questionários: um é realizado pela gestão escolar, com o objetivo de analisar os fatores associados à aprendizagem e o outro é direcionado aos estudantes com o objetivo de coletar informações sobre o contexto social, econômico, cultural e familiar destes (SÃO PAULO, 2009; 2014b).

O instrumento avaliativo é aplicado anualmente aos alunos dos $2^{\circ}, 3^{\circ}, 5^{\circ}, 7^{\circ}$ e $9^{\circ}$ anos do ensino fundamental ${ }^{10}$ e $3^{\circ}$ ano do ensino médio, nos componentes de Língua

\footnotetext{
${ }_{10}$ A participação dos alunos do $2^{\circ}$ ano do ensino fundamental deu-se a partir do ano de 2013 , com a intenção de acompanhar a meta do
} 
Portuguesa e Matemática ${ }^{11}$, e é orientado por uma matriz de referência baseada no currículo do Estado de São Paulo. No caso dos anos iniciais, as bases conceituais de elaboração das provas baseiam-se no projeto "Ler e Escrever", utilizado desde o ano de 2007 nas escolas estaduais de $1^{\mathrm{a}}$ a $4^{\mathrm{a}}$ série $^{12}$ do Estado de São Paulo (SÃO PAULO, 2009).

O SARESP é aplicado desde o ano de 1996 e, em 2007, passou por algumas reformulações, as quais foram implementadas no ano seguinte, tais como: o teste dos itens das provas, a introdução de itens com respostas construídas pelos alunos (para verificação da construção do pensamento lógico matemático), a ampliação da aplicação da prova para todas as áreas do conhecimento (ainda que em anos alternados) e a adequação das habilidades aferidas nesta avaliação ao Sistema de Avaliação da Educação Básica/Saeb/Prova Brasil permitindo assim uma comparação de resultados em nível nacional. (SÃO PAULO, 2009).

Após a sua aplicação, são gerados documentos - boletins e relatórios de desempenho, relatórios técnicos e relatórios pedagógicos - que têm por objetivo contribuir para a definição das ações pedagógicas nas instituições escolares, sendo que "os principais destinatários destes resultados são os professores" (SÃO PAULO, 2014a, p. 08).

Tais documentos revelam o cenário da educação estadual paulista e possibilitam observar quais aspectos necessitam de maior atenção durante o processo de ensino e aprendizagem, além de auxiliarem os docentes nas tomadas de decisões durante 0 planejamento de atividades a serem desenvolvidas. Como diz Bitar (1998), os resultados representam uma bússola para a reorientação do trabalho das escolas e das instâncias da Secretaria da Educação.

Mas, de que forma essas avaliações são elaboradas? Como já indicamos, o instrumento avaliativo é elaborado a partir de uma matriz de referência, apoiada na Proposta Curricular do Estado de São Paulo. Para os anos iniciais está pautada no projeto "Ler e Escrever" e, nos anos finais do ensino fundamental e ensino médio, pauta-se no currículo em exercício na rede estadual paulista, desde agosto de 2007. "Os conteúdos, competências e habilidades apontados na proposta, para cada série e disciplina do currículo, indicam as bases conceituais da matriz para a avaliação" (SÃO PAULO, 2009, p. 11).

As habilidades são indicadores das aprendizagens que se espera dos alunos e, na escala de proficiência, é possível inferir o nível de desenvolvimento destas habilidades. Quanto aos conteúdos, a matriz não contempla a todos, pois faz um recorte com as estruturas conceituais mais gerais da disciplina.

No quadro ${ }^{13}$ a seguir apresentamos os níveis de desempenho em que as crianças matriculadas no $2^{\circ}$ ano do ensino fundamental são classificadas, no componente de Língua Portuguesa, após a realização da avaliação em larga escala do estado de São Paulo.

Quadro 2 - Descrição dos níveis de desempenho dos alunos do $2^{\circ}$ ano do ensino fundamental - Língua Portuguesa

\begin{tabular}{|c|l|}
\hline Nível de desempenho & \multicolumn{1}{|c|}{ Descrição } \\
\hline Insuficiente & $\begin{array}{l}\text { Os alunos classificados neste nível escrevem com correspondência sonora ainda não alfabética, de- } \\
\text { monstrando domínio insuficiente sobre as regras de geração da escrita. }\end{array}$ \\
\hline
\end{tabular}

Governo do Estado de São Paulo, da plena alfabetização das crianças até os sete anos de idade (SÃO PAULO, 2014).

11 Os outros componentes são avaliados em anos alternados.

12 Com a ampliação do ensino fundamental para nove anos, o material também foi reformulado e passou a adotar a nomenclatura de $1^{\circ}$ a $5^{\circ}$ ano.

13 Optamos por descrever o texto na íntegra referente ao Relatório Pedagógico de 2014. As diferenças existentes entre as descrições dos níveis de desempenho dos anos de 2013 e 2014 referem-se ao gênero textual utilizado nos diferentes anos de sua realização. No ano de 2013, o gênero utilizado foi a quadrinha. A outra diferença observada é que na descrição de 2014 o texto de memória é definido como a cantiga e em 2013 não havia a definição do gênero do texto de memória. 


\begin{tabular}{|c|l|}
\hline Básico & $\begin{array}{l}\text { Os alunos classificados neste nível escrevem com correspondência sonora alfabética, realizam sepa- } \\
\text { rações entre palavras de uma parlenda, mas nem sempre de forma convencional, localizam algumas } \\
\text { palavras de um texto (cantiga) memorizado oralmente e, na leitura, informação explícita apresentada } \\
\text { em texto informativo. Em situações de produção textual com apoio, reescrevem trecho de uma história } \\
\text { conhecida, garantindo a presença de alguns dos acontecimentos narrados e articulando parcialmente } \\
\text { os trechos do texto, e, em consequência, apresentando quebras da coerência que resultam alguns } \\
\text { problemas de compreensão. }\end{array}$ \\
\hline Pleno & $\begin{array}{l}\text { Os alunos classificados neste nível escrevem com correspondência sonora alfabética, realizam, de } \\
\text { forma convencional, separações entre palavras de uma parlenda, localizam a maioria das palavras } \\
\text { de um texto (cantiga) memorizado oralmente e, na leitura, informação explícita apresentada em texto } \\
\text { informativo. Em situações de produção textual com apoio, reescrevem trecho de uma história conhe- } \\
\text { cida, garantindo a presença de mais da metade dos acontecimentos narrados e, ainda que com uma } \\
\text { ou duas falhas, articulam coerentemente os trechos do texto produzido, de modo a não comprometer } \\
\text { a coerência da produção textual. }\end{array}$ \\
\hline $\begin{array}{l}\text { Os alunos classificados neste nível escrevem com correspondência sonora alfabética e ortografia re- } \\
\text { gular, realizam, de forma convencional, separações entre palavras de uma parlenda, localizam qua- } \\
\text { se todas as palavras de um texto (cantiga) memorizado oralmente e, na leitura, informação explícita } \\
\text { apresentada em texto informativo. Em situações de produção textual com apoio, reescrevem trecho de } \\
\text { uma história conhecida, garantindo a presença da maioria dos acontecimentos narrados, e articulam } \\
\text { coerentemente os trechos do texto produzido, sem provocar problemas de compreensão. }\end{array}$ \\
\hline Avançado
\end{tabular}

Fonte: SÃO PAULO (2014c, p. 18).

A prova do $2^{\circ}$ ano do ensino fundamental apresenta questões que "aferem a aprendizagem básica em leitura e, em especial, o desenvolvimento das habilidades de escrita" (SÃO PAULO, 2015, p. 11). Os resultados classificam os alunos em quatro níveis de desempenho: insuficiente, básico, pleno e avançado. Já os alunos dos $3^{\circ}, 5^{\circ}, 7^{\circ}$ e $9^{\circ}$ anos do ensino fundamental e os alunos do $3^{\circ}$ ano do ensino médio são classificados em três grupos: insuficiente, suficiente e avançado, que por sua vez são agrupados em quatro níveis de proficiência: abaixo do básico, básico, adequado e avançado. Estes últimos níveis de proficiência também representam a escala numérica do Saeb, o que permite uma comparação em nível nacional dos alunos a partir do $3^{\circ}$ ano do ensino fundamental.

\section{O ENSINO DA LÍNGUA MATERNA NA REDE PARTICULAR E OS RESULTADOS DO SARESP}

A pesquisa que originou este artigo analisou os resultados das edições de 2013 e 2014 , dos $2^{\circ}$ e $3^{\circ}$ anos do ensino fundamental no componente de Língua Portuguesa em uma das escolas da rede SESI - SP. Como explicitado no tópico que apresenta especificamente a constituição do SARESP, esta é uma avaliação em larga escala que tem por objetivo diagnosticar o desempenho dos alunos matriculados na rede estadual. As escolas particulares podem participar, por adesão, e também recebem os boletins de desempenho com a classificação dos alunos nos níveis de proficiência.

Por termos trabalhado com os resultados dos $2^{\circ}$ e $3^{\circ}$ anos do ensino fundamental, especificamente no componente de Língua Portuguesa, nosso olhar voltou-se ao ensino da língua materna nesta rede de ensino.

Em atendimento às mudanças dos artigos 29, 30, 32 e 87 da Lei de Diretrizes e Bases da Educação (BRASIL, 1996), por meio da Lei n. ${ }^{0} 11.274 / 2006$, o SESI amplia a duração do ensino fundamental de oito para nove anos e, paralelo a este processo, implementa o ensino em tempo integral, ampliando a permanência das crianças na escola. Então, nosso público participante da avaliação externa nos anos de 2013 e 2014 já havia se adequado à nova estrutura do ensino fundamental.

Esta rede de ensino possui material didático próprio, tanto para o ensino fundamental quanto para o ensino médio, o qual foi elaborado entre os anos de 2009 e 2013 e, com o objetivo de contribuir para a elevação da qualidade educacional, a rede SESI passou a realizar convênios com outras instituições e a concepção pedagógica passou a ser implantada em diferentes municípios do estado de São Paulo. 
Sua concepção de educação engloba ensino, aprendizagem e pesquisa, numa abordagem sociointeracionista, que "considera o conhecimento como processo de construção fundado no diálogo permanente entre professores e estudantes" (SESI, 2015, p. 28). Tal concepção recebeu contribuições da teoria do psicólogo L. S. Vygotsky, do biólogo e epistemólogo Jean Piaget, do médico, psicólogo e educador Henri Wallon e também do pesquisador norte-americano David Ausubel. A organização curricular prevê a interdisciplinaridade dos componentes curriculares, a dialogicidade, a contextualização dos conteúdos escolares e também desenvolvem as perspectivas de ensino e aprendizagem pautadas em competências e habilidades, indicadas a partir das expectativas de ensino e aprendizagem ${ }^{14}$ para cada componente curricular. Ainda apresentam metas a serem alcançadas em cada ano escolar, as quais organizamos no quadro 3.

Quadro 3 - Metas de aprendizagem do $1^{\circ}$ ao $3^{\circ}$ ano do ensino fundamental no componente de Língua Portuguesa no Sistema SESI - SP

\begin{tabular}{|c|c|}
\hline Ano & Metas \\
\hline $1^{0}$ & $\begin{array}{l}\text { - O domínio da escrita com hipótese alfabética; } \\
\text { - A leitura convencional e/ou utilização de estratégias que permitam a leitura; } \\
\text { - O uso da linguagem oral com coerência (encadeamento de ideias, fatos e ações); } \\
\text { - A produção de textos escritos (de acordo com os conhecimentos que possui sobre a escrita); } \\
\text { - A interpretação e compreensão de textos diversos; } \\
\text { - O reconto de diferentes textos. }\end{array}$ \\
\hline $2^{0}$ & $\begin{array}{l}\text { - A leitura autônoma e convencional; } \\
\text { - A produção de textos escritos com o uso de convenções da escrita: regularidades diretas, irregularidades de uso co- } \\
\text { mum, maiúscula no início de frases e nomes próprios e sinais de pontuação: ponto - final, interrogação, exclamação e } \\
\text { parágrafo; } \\
\text { - A interpretação e a compreensão de textos diversos; } \\
\text { - O reconto e a reescrita de diferentes textos. }\end{array}$ \\
\hline $3^{0}$ & $\begin{array}{l}\text { - A leitura autônoma e convencional; } \\
\text { - A produção de textos escritos com o uso de convenções da escrita: regularidades diretas, irregularidades de uso comum, } \\
\text { maiúscula no início de frases e nomes próprios e sinais de pontuação: ponto - final, interrogação, exclamação, vírgula, } \\
\text { parágrafo e dois -pontos; } \\
\text { - Os aspectos ortográficos relacionados a regularidades morfológicas, gramaticais e contextuais podem ser trabalhadas } \\
\text { de acordo com as dificuldades das crianças em situações de produção de texto, porém não tem caráter obrigatório ao } \\
\text { final deste ano. }\end{array}$ \\
\hline
\end{tabular}

Fonte: SESI (2010, p. $44-45)$.

As expectativas de ensino e aprendizagem mantêm-se de um ano para o outro (algumas são iguais nos três anos e outras se repetem no $2^{\circ}$ e no $3^{\circ}$ anos do ensino fundamental) e são as metas (quadro 3) que dão um parâmetro da progressão de trabalho. A partir delas, é possível compreender com clareza o que se espera do aluno em cada ano escolar.

Observamos que ao final do $2^{\circ}$ ano espera-se que o aluno já produza textos escritos, utilize letra maiúscula e os sinais de pontuação. Ao compararmos com os níveis de desempenho da avaliação externa, verificamos que se espera que as crianças estejam num nível de desempenho elevado, com conhecimentos que não são avaliados no SARESP, o que nos leva a questionar mais uma vez a diferença de resultados nas edições de 2013 e 2014.

A proposta curricular do SESI, fundamentada na abordagem sociointeracionista, prevê que o ensino da língua materna compreenda a aprendizagem desta como um processo dinâmico que não pode se restringir à análise de formas linguísticas. O trabalho

\footnotetext{
${ }_{14}$ A organização curricular do estado de São Paulo também está pautada nas expectativas de ensino e aprendizagem.
} 
com a reflexão da língua, através dos gêneros textuais, deverá ampliar o domínio que o aluno tem sobre ela e capacitá-lo a produzir textos orais e escritos adequados à situação comunicativa.

Sendo assim, para o desenvolvimento da competência comunicativa oral, propõe que os alunos participem de situações de respeito às diferentes opiniões, de argumentação e de adequação aos contextos comunicativos. A leitura é compreendida como conteúdo a ser ensinado e, para isso, os alunos devem ter acesso aos diferentes gêneros textuais, a partir de uma rotina de leitura. Nestes momentos, com diferentes intencionalidades, é importante que os alunos conheçam "os propósitos da leitura (ler por prazer, ler para aprender, ler para conhecer, ler para informar-se...), pois, não poderá ler do mesmo modo diferentes textos" (SESI, 2015, p. 72).

Percebemos, então, que os gêneros textuais sustentam o trabalho com o ensino da língua materna, sistematizados através das sequências didáticas. Analisamos os materiais didáticos do $1^{\circ}$ ao $3^{\circ}$ ano do ensino fundamental, no componente de Língua Portuguesa, e identificamos os gêneros contemplados para o trabalho com a sequência didática. Nesta sequência, os alunos vivenciam momentos de aproximação, conhecimento das características e função do gênero textual, além de momentos em que realizam a escrita, reescrita, revisão e, até mesmo, produção de escrita de autoria (quando o aluno tem a oportunidade de criar o seu texto). Baseado na proposta dos agrupamentos dos gêneros textuais de Scheneuwly e Dolz (2014), organizamos ${ }^{15}$, no próximo quadro, os textos que os alunos do SESI - SP, do $1^{\circ}$ ao $3^{\circ}$ ano, têm a oportunidade de conhecer a partir do material didático utilizado nesta rede de ensino.

Quadro 4 - Gêneros textuais contemplados no material didático do Sistema SESI no componente de Língua Portuguesa

\begin{tabular}{|c|c|c|c|}
\hline Agrupamento & $1^{0}$ ano & $2^{\circ}$ ano & $3^{\circ}$ ano \\
\hline NARRAR & $\begin{array}{c}\text { Contos de fadas, fábula, } \\
\text { parlendas, trava - língua. }\end{array}$ & Contos de bruxa, tirinha. & Conto, lendas. \\
\hline EXPOR & Ficha técnica, lista. & $\begin{array}{c}\text { Tabela, relatório científico, curiosidade, } \\
\text { texto expositivo, cartaz. }\end{array}$ & Divulgação científica, entrevista, lista. \\
\hline ARGUMENTAR & Classificados, carta. & Carta & \\
\hline INSTRUIR/ & Receita, texto instrucional. & Texto instrucional de experimento, receita & \\
\hline RESCREVER & Convite, notícia, biografia. & $\begin{array}{c}\text { Entrevista, agenda, biografia, relato de } \\
\text { experiência vivida, cartão postal, e-mail. }\end{array}$ & $\begin{array}{c}\text { Causo, anedotas, noticia, reportagem, } \\
\text { biografia e autobiografia. }\end{array}$ \\
\hline
\end{tabular}

Fonte: Organizado pelas pesquisadoras a partir do material didático da rede SESI -SP (2010).

Observamos, então, que os alunos são repertoriados com diversos gêneros textuais, estratégia de suma importância para o processo de alfabetização e letramento da criança.

O Sistema possui, ainda, um volume intitulado "Muitos textos...tantas palavras" para cada ano escolar, com uma coletânea de diferentes gêneros textuais, para ampliar o repertório dos alunos e aprofundar os assuntos estudados. O livro "contém uma seleção de textos, cujo critério está ancorado na qualidade, na adequação e na variedade de gêneros textuais" (SESI, 2010, p. 40).

O sistema avaliativo da rede SESI - SP fundamenta-se nas diferentes dimensões da avaliação educacional: a avaliação institucional, a avaliação de programas e projetos, a avaliação de sistemas e a avaliação da aprendizagem, as quais interagem e podem dar suporte umas às outras. Por atender o disposto na Lei de Diretrizes e Bases da Educação Nacional 9394/96 (BRASIL, 1996), artigo 24, que assegura "a avaliação contínua e cumulativa do desempenho do aluno, com prevalência dos aspectos qualitativos sobre os quantitativos e dos resultados ao longo do período sobre os de eventuais provas

\footnotetext{
$\overline{15}$ Para esta organização, analisamos o material didático do aluno, no componente de Língua Portuguesa, do $1^{\circ}$ ao $3^{\circ}$ ano do ensino fundamental.
} 
finais", observamos que a rede dá ênfase à perspectiva da avaliação formativa, a qual exige de seus docentes uma postura diferenciada na ação avaliativa.

Além desta ênfase na perspectiva da avaliação formativa, durante o processo de aprendizagem, também identificamos uma valorização dos resultados da avaliação de sistemas no momento da definição das ações do plano de gestão da escola. Há a indicação de que os resultados externos devem ser confrontados com os resultados obtidos com as avaliações internas e, "diante deles, produzir diretrizes, planejar e executar ações" (SESI, 2015, p. 49). Porém, este confronto não deverá considerar apenas os instrumentos avaliativos, e, sim, todo o processo de aprendizagem que o aluno percorreu. Portanto, a perspectiva da avaliação formativa, se bem compreendida e executada, contribuirá para o ensino e a aprendizagem.

No momento da realização da pesquisa, a rede de ensino não possuía um sistema próprio de monitoramento da qualidade educacional, ou seja, não possuía um sistema de testes padronizados para a verificação do desempenho dos alunos em seu sistema educacional. Desta forma, por meio de adesão, começou a participar do SARESP. Aqui emerge uma das questões que movimentaram nossa pesquisa: o que os resultados do SARESP estariam indicando em relação ao desempenho dos alunos na rede SESI? Como estes resultados contribuem (ou não) na prática das docentes? De que forma as docentes veem a realização desta avaliação na rede SESI?

Os resultados das edições analisadas na pesquisa (MACHADO, 2017) indicaram uma mudança significativa nos indicativos dos níveis de proficiência no $2^{\circ}$ ano do ensino fundamental, em Língua Portuguesa, na rede SESI. A escola selecionada para ser objeto de investigação também apresentava essa significativa mudança. Compilamos os resultados no quadro 5 .

Quadro 5 - Resultados do $2^{\circ}$ ano do ensino fundamental no SARESP em Língua Portuguesa

\begin{tabular}{c|cc|cc}
\hline \multirow{2}{*}{ Níveis de proficiência } & \multicolumn{2}{|c|}{ Rede SESI - SP } & \multicolumn{2}{c}{ Unidade escolar } \\
& 2013 & 2014 & 2013 & 2014 \\
\hline Insuficiente & 1,0 & 0,2 & 0 & 0 \\
Básico & 10,6 & 24,2 & 9,4 & 64,5 \\
Pleno & 24,3 & 44,8 & 21,9 & 9,7 \\
Avançado & 64,1 & 30,9 & 68,8 & \\
\hline
\end{tabular}

Fonte: Organizado pelas pesquisadoras (2017)

$\mathrm{Na}$ primeira edição em que os alunos do $2^{\circ}$ ano participaram do SARESP, apresentaram um resultado percentual satisfatório, considerando que $68,8 \%$ dos alunos encontravam-se no avançado. Porém, no ano seguinte, esse índice diminuiu consideravelmente e indicou um aumento nos níveis anteriores: o básico e o pleno. A mesma situação aconteceu com o resultado da rede: na edição de 2013 , alcançou um percentual de $64,1 \%$ dos alunos no nível de proficiência avançado e, no ano seguinte, esse índice reduziu para menos da metade.

Considerando a valorização dos resultados da avaliação em larga escala para a definição das ações do plano de gestão e indicação da importância do confronto dos resultados do teste padronizado com a avaliação realizada pelo professor, optamos por dar voz às docentes e conhecer o uso destes resultados na unidade escolar. Para isto, organizamos uma entrevista semiestruturada, dividida em alguns eixos de investigação. Trataremos no tópico seguinte, apenas o eixo destinado à avaliação escolar, o que inclui os resultados do SARESP e as práticas pedagógicas oriundas desta dimensão avaliativa.

5 O SARESP NA REDE SESI - SP: a voz das docentes

A participação dos alunos matriculados no $2^{\circ}$ ano do ensino fundamental deu-se a partir do ano de 2013, tanto para a rede estadual quanto para as escolas que participam 
por meio de adesão. Especificamente, no caso do SESI - SP, observamos a mudança significativa nos índices de proficiência, em toda a rede escolar (como demonstra o quadro 5). Analisamos as provas para verificarmos se havia mudanças, as quais poderiam ser a causa da oscilação de resultados, e observamos que as habilidades e o tipo de questões permaneceram as mesmas. Foi chegada a hora de conhecer a representatividade do SARESP em uma das unidades escolares do SESI e, para isso, entrevistamos cinco docentes do $1^{\circ}$ ao $5^{\circ}$ ano do ensino fundamental.

Entre outros eixos, igualmente importantes, a entrevista realizada com as docentes nos revelou um cenário em que os resultados da avaliação são apresentados aos professores em reuniões; que tais índices são comparados ano a ano; que há ações planejadas a serem realizadas ao longo do ano letivo com o intuito de preparar os alunos para a realização da prova; que compreendem a realização desta avaliação desconectada com o currículo do SESI; que há a existência do ranking entre as escolas da rede e que, em algumas situações, as docentes se sentem responsabilizadas por tais resultados.

Durante as entrevistas com as docentes, observamos que há dois momentos em que os resultados dos alunos são apresentados e tratados: coletiva e individualmente. Os momentos coletivos são as reuniões pedagógicas ou as reuniões denominadas como Discussão Pedagógica Coletiva $\left(\mathrm{DPC}^{16}\right)$. Nas reuniões coletivas, os resultados são apresentados a toda equipe e são comparados com os anos anteriores:

\begin{abstract}
São feitas reuniões e eles tentam comparar [...] compara resultado de $2012 \mathrm{com}$ resultado de 2013 [...] resultado de 2013 com resultado de 2014 [...] ou senão mostra como está sendo destes três anos [...] se a gente está avançando [...] se a gente está no mesmo nível [...] ou se regrediu (DOCENTE A $-3^{\circ}$ ano, 2015).

Sempre na DPC [...] tem devolutiva [...] de como foi o resultado da nossa escola e é avaliado perante todo o grupo [...] que as vezes está todo mundo junto [...] do $1^{\circ}$ ao $9^{\circ}$ ano [...] e o médio[...] o resultado da sala (DOCENTE D - $2^{\circ}$ ano, 2015).

A primeira vez que a gente trabalhou o resultado do SARESP foi um trabalho bem intenso no SESI [...] aí teve aquele negócio de cluster [...] aí você tinha quem estava no nível 1 ...2......e tinha que atingir o nível $1[\ldots]$ o nível $2[\ldots]$ e fez todo um estudo $[\ldots]$ o que estava errado [...] o que faltou [...] o problema está nisso [...] então vamos fazer formação nisso [...] (DOCENTE C $-4^{\circ}$ ano, 2015).
\end{abstract}

Inferimos durante as falas duas situações: um certo constrangimento com a divulgação dos resultados coletivamente e a responsabilização pelos índices alcançados. Esta última situação fica clara no momento em que uma das docentes cita ter sido chamada individualmente para ter ciência do resultado da sua turma no SARESP e, depois, apresentar este mesmo resultado na reunião coletiva. Outra docente ainda cita que, nas reuniões coletivas, há um tempo destinado à discussão dos resultados desta avaliação externa. Percebemos tal situação quando a professora nos relata: "nas reuniões que são feitas pra isso mesmo [...] tem lá, por exemplo, [...] hoje nós vamos discutir SARESP [...] quem conseguiu e quem não conseguiu [...] vamos pedir para quem conseguiu falar o que fez [...]" (DOCENTE C - $4^{\circ}$ ano, 2015).

Tal situação converge com o fato do constrangimento e da responsabilização de resultados por um único docente. Temos que considerar que seja uma sequência de trabalho pedagógico, no qual a mesma turma passará por diferentes professores e, quando há essa responsabilização, desconsidera-se a coletividade do trabalho pedagógico.

Após a apresentação dos resultados, as docentes recebem os nomes dos alunos e o nível de proficiência em que se encontram para que possam comparar com a

${ }^{16}$ DPC (Discussão Pedagógica Coletiva) - reuniões semanais, às quartas-feiras, com os docentes do $1^{\circ}$ ao $9^{\circ}$ ano do ensino fundamental, que desenvolvem o trabalho pedagógico com os alunos do período integral. Neste horário, os alunos são dispensados.

Cad. Pesq., São Luís, v. 26, n. 3, p. 145-163, jul./set., 2019. 
avaliação realizada em sala de aula. Neste momento, surgem situações em que os resultados revelam divergência e outros que convergem com a avaliação da docente:

Não, normalmente nunca bate [...] um ou outro aluno você olha e fala assim [...] nossa é verdade [...] mas no geral fica muito diferente do que você vê [...] às vezes tem essa surpresa sim [...] a sala é boa e às vezes ela está abaixo [...] aí você começa a se questionar [...] ou estou sendo boazinha demais e não estou enxergando [...] porque você começa a se exigir. (DOCENTE C $-4^{\circ}$ ano, 2015).

[...] foi divergente [...] uns surpreenderam [...] diariamente em provas que a gente aplicou na sala de aula [...] alunos que vão muito bem [...] têm resultados muito positivos [...] no SARESP apresentou o nível básico [...] outros alunos que têm uma dificuldade extrema [...] dificuldade que eu digo desde $01^{\circ}$ ano [...], eles passaram bem [...] alguns que nós estávamos esperando para o nível básico não apareceu [...] dois que sempre foram bem apareceram lá (DOCENTE $B-1^{\circ}$ ano, 2015).

[...] até nesse último que foi feito que é a turma que está comigo [...] tem aluno que estava no avançado [...] e para mim tem uma dificuldade gigante. (DOCENTE A - $3^{\circ}$ ano, 2015).

Porém, apesar de compararem com os resultados da avaliação da aprendizagem realizada por elas em sala de aula, fica implícito que o resultado do SARESP possui um peso significativo e gera mudanças na prática pedagógica. Pois, após a apresentação dos resultados e das habilidades que ficaram em defasagem, as docentes organizam ações a serem realizadas durante o ano letivo. Essas ações são representadas, principalmente, pela organização e execução de simulados com a estrutura deste instrumento avaliativo ou, até mesmo, com o uso das questões utilizadas em edições anteriores. Essas ações acontecem semanal ou mensalmente, o que vai indicar a periodicidade é o ano escolar em que a docente está lecionando:

No $1^{\circ}$ ano não há uma periodicidade...nos outros anos sim [...]. (DOCENTE B - $1^{\circ}$ ano, 2015).

[...] sempre pede uma vez por semana pra gente colocar alguma coisa. (DOCENTE $D-2^{\circ}$ ano, 2015).

[...] essa turminha que eu recebi estava com mais dificuldades [...] então a gente colocou trabalhar geral [...] trabalhar tudo [...] desde segmentação até a produção (DOCENTE $A-3^{\circ}$ ano).

[...] agora no $4^{\circ}$ ano não porque $\circ 4^{\circ}$ ano não presta o SARESP [...] então você faz tipo um trabalho preparatório [...] avaliação objetiva[...] faz esse trabalho mas não tem aquele foco de SARESP...você faz para ir identificando [...] simulado [...] perguntas do SARESP [...] respostas do SARESP [...] modelos de provas do SARESP (DOCENTE $\mathrm{C}-4^{\circ}$ ano).

[...] eu tenho que descrever no plano que eu trabalharei os descritores do SARESP [...] já recebi devolutiva que eu não havia colocado e tinha que colocar. (DOCENTE $E-5^{\circ}$ ano).

Primeiramente, cada uma analisa o seu e traça as metas que faria [...] depois em outro momento as coordenadoras juntam e socializam essas ações [...]. (DOCENTE B $-1^{\circ}$ ano, 2015).

Nestas falas, observamos uma outra situação que indica o peso do teste padronizado: a necessidade de indicar no planejamento as ações que serão desenvolvidas de acordo com as habilidades do SARESP e a devolutiva da coordenação pedagógica, ao docente, apontando a ausência deste trabalho em seu planejamento de aulas:

[...] eu tenho que descrever no plano que eu trabalharei os descritores do SARESP [...] eu já recebi devolutiva que eu não havia colocado e tinha que colocar [...] que estava faltando isso no meu plano [...] (DOCENTE E $-5^{\circ}$ ano, 2015). 
[...]você coloca no seu planejamento mensal [...] atividades diferenciadas visando a avaliação externa [...] (DOCENTE C $-4^{\circ}$ ano, 2015).

[...] nesse ano no meu primeiro plano eu não coloquei nada de atividade relacionado ao SARESP e aí foi pontuado que não colocou nada relacionado à avaliação externa (DOCENTE D - $2^{\circ}$ ano, 2015).

Entretanto, o fato de trabalharem as atividades relacionadas ao SARESP com o objetivo de prepararem os alunos para a realização desta avaliação no final do ano letivo, não significa que concordem com essa postura. Na sequência, apresentamos alguns trechos das entrevistas em que as docentes compartilham a discordância da preparação dos alunos para realização da prova.

Eu acho que não...porque o que eu acredito e o que o SESI tem como proposta [...] não é só basear nessa prova [...] porque às vezes a gente acaba [...] focando só nisso [...] num resultado [...] é um resultado de classificação [...] e a parte da formação mesmo... dele entender...compreender aquilo...fazer um sentido para ele [...] às vezes se perde [...] nós temos essa cobrança e a gente acaba passando pra criança (DOCENTE $B$ - $1^{\circ}$ ano, 2015).

Eu acho que se ele está preparado para dentro do nosso conteúdo [...] ele está pronto para fazer a avaliação externa (DOCENTE D $-2^{\circ}$ ano, 2015).

Eu acredito que não...porque o nosso trabalho é muito diferente do trabalho desenvolvido no Estado [...] que é mais voltado para o SARESP...faz parte da rede deles [...] e acaba excluindo essa avaliação formativa que a gente faz [...] que é todo o processo de trabalho (DOCENTE A - $3^{\circ}$ ANO, 2015).

Preparar não[...] eu pessoalmente não gosto de preparar o aluno para isso [...] eu acho que se tem que trabalhar bem os conteúdos da nossa rede [...] eles vão fazer um bom SARESP [...] mas eu preparo [...] com simulados [...] porque eu tenho [...] eu quero que ele tenha um bom resultado no SARESP [...] é exigido que ele tenha um bom resultado no SARESP (DOCENTE E $-5^{\circ}$ ano, 2015).

Após verificarmos que as docentes praticam o treino e preparo para a avaliação externa, concluímos, em consenso com Lima (2013), que o treino, o uso dos simulados e instrumentos avaliativos semelhantes à prova externa não mudam os resultados finais. A mudança significativa do resultado do $2^{\circ}$ ano do ensino fundamental, nas edições de 2013 e 2014 clarifica essa situação (as docentes treinaram, mas os resultados não progrediram).

As docentes também compartilharam, durante as entrevistas, que a aplicação do SARESP tem como objetivo comparar com alunos do estado e município, avaliar a escola e comparar com as outras e, ainda, ganhar visibilidade:

[...] comparação com alunos do estado e município [...] (DOCENTE D - $2^{\circ}$ ano, 2015).

[...] avaliar o nível de ensino e aprendizagem da escola [...] relacionado às outras escolas [...] (DOCENTE B $-1^{\circ}$ ano, 2015).

[...] avaliar o aluno e ver se ele está conseguindo acompanhar o que o SARESP propõe [...] (DOCENTE E - $5^{\circ}$ ano, 2015).

[...] comparar e ganhar visibilidade[...] (DOCENTE C $-4^{\circ}$ ano, 2015).

De diferentes formas, a importância desta avaliação aparece novamente nestas falas e revela que as docentes o enxergam como instrumento de controle e comparação e não como mais um instrumento avaliativo que possa auxiliar o trabalho pedagógico. Talvez tal compreensão exista pela forma como os resultados são tratados e ganham visibilidade no ranking entre as escolas. Uma delas até cita ser desnecessário essa comparação, pois "são realidades completamente diferentes" (DOCENTE C- $4^{\circ}$ ano, 
2015). A prática do ranking acaba por estimular a competitividade entre docentes e escolas e cria o risco de perder o foco principal: a aprendizagem dos alunos.

As entrevistas contribuíram para que pudéssemos conhecer um pouco mais sobre a representatividade desta avaliação na escola e os desdobramentos do uso de seus resultados a partir de comparativos entre unidades escolares e até mesmo entre docentes, resultando na prática do treino para elevar resultados e a ausência de momentos de reflexão da concretização da concepção de ensino adotada pela rede particular.

Uma das fases da nossa pesquisa baseou-se no comparativo entre as expectativas de ensino e aprendizagem do $1^{\circ}$ ao $3^{\circ}$ ano do ensino fundamental em Língua Portuguesa com as habilidades aferidas nas provas do $2^{\circ}$ e do $3^{\circ}$ ano do SARESP. Nesta etapa, observamos que todas as habilidades aferidas são contempladas em diferentes expectativas da rede particular. Sendo assim, acreditamos que o foco de trabalho formativo seja verificar o como essas expectativas estão sendo desenvolvidas e não aplicar questões para treinar os alunos.

\title{
6 CONSIDERAÇÕES FINAIS
}

Os resultados aqui apresentados proporcionaram diferentes reflexões ao longo da realização da pesquisa (MACHADO, 2017) e, para este artigo, privilegiamos aquelas direcionadas às mudanças nas práticas pedagógicas geradas após a divulgação dos índices de desempenho do SARESP na unidade escolar da rede particular.

Os alunos do $2^{\circ}$ ano do ensino fundamental iniciaram sua participação nesta avaliação no ano de 2013, com o objetivo da Secretaria Estadual de Educação do Estado de São Paulo (SEE/SP) acompanhar a meta da alfabetização ${ }^{17}$ das crianças até os sete anos de idade. Analisamos as edições de 2013 e 2014 na rede particular, e, verificamos que os alunos tiveram, na primeira edição, um resultado satisfatório, apresentando 68,8 \% classificados no nível de desempenho avançado.

Os alunos classificados neste nível escrevem com correspondência sonora alfabética e ortografia regular, realizam, de forma convencional, separações entre palavras de uma parlenda, localizam quase todas as palavras de um texto (cantiga) memorizado oralmente e, na leitura, informação explícita apresentada em texto informativo. Em situações de produção textual com apoio, reescrevem trecho de uma história conhecida, garantindo a presença da maioria dos acontecimentos narrados, e articulam coerentemente os trechos do texto produzido, sem provocar problemas de compreensão (SÃO PAULO, 2014c, p. 18).

Após ler a descrição desta classificação, comparamos com as metas apresentadas pelo SESI, as quais balizam o trabalho dos professores com as expectativas de ensino e aprendizagem. Duas metas do $2^{\circ}$ ano indicam que o trabalho proposto vai além do que está sendo solicitado na prova.

\begin{abstract}
Meta: A produção de textos escritos com o uso de convenções da escrita: regularidades diretas, irregularidades de uso comum, maiúscula no início de frases e nomes próprios e sinais de pontuação: ponto final, interrogação, exclamação e parágrafo.
\end{abstract}

Meta: O reconto e a reescrita de diferentes textos (SESI, 2010, p. 44 - 45).

No momento em que a criança, ao final do $2^{\circ}$ ano, está sendo avaliada por meio da prova do SARESP, espera-se que reescreva, em uma das questões, um texto de memória e, a questão mais complexa, solicita a reescrita de um trecho de uma história conhecida. De acordo com a meta apresentada, o aluno matriculado neste mesmo ano escolar, na rede particular, deverá produzir textos escritos com a presença até mesmo de alguns sinais de pontuação. Consideramos, então, que a prova está aferindo habilidades

17 Disponível em:< http://www.educacao.sp.gov.br/alfabetizacao>. Acesso em: 05 jan. 2018. 
aquém daquelas propostas no material da rede particular, as quais já deveriam estar absorvidas pelos alunos.

Outra observação em relação à meta é que as crianças devam chegar ao final do ano letivo com domínio do uso de letras maiúsculas no início de frases e nomes próprios, o que nos indica o uso da letra manuscrita. Num outro comparativo com o SARESP, encontramos essa habilidade sendo aferida apenas na prova do $3^{\circ}$ ano. Mais uma vez, encontramos indícios de que a proposta da rede vai além das questões da prova. Também verificamos que os gêneros textuais utilizados no instrumento avaliativo são contemplados no material didático, o que também indica que a criança já tenha conhecimento de sua estrutura e função.

Estas observações, resultado da comparação entre a descrição do nível de desempenho avançado e das metas da rede particular para o $2^{\circ}$ ano, nos levam a questionar sobre as práticas pedagógicas realizadas em sala: se a proposta do material vai além do que é verificado na prova; por que o resultado não está evidenciado nos índices de desempenho? Outra questão, importante neste momento, é relembrar que as matrizes de referência "representam um recorte dos conteúdos do currículo e também privilegia algumas competências e habilidades a eles associados" (SÃO PAULO, 2009, p. 14). Mais uma vez, retornamos na questão anterior: qual o motivo das crianças ainda apresentarem dificuldades em habilidades tão simples como a escrita de palavras em uma lista?

Os resultados nos trazem questionamentos da prática pedagógica e as entrevistas nos revelam que as docentes são levadas a treinar os alunos para a realização do SARESP. Como pontuou Lima (2013, p. 56), "um dos maiores equívocos cometidos por redes inteiras reside em acreditar que é possível modificarmos os resultados ou alterarmos os índices dos exames externos [...] por meio de simulados e treinos". Desta forma, os resultados nos indicam claramente que treinar os alunos, aplicar simulados e resolver questões de outras edições desta avaliação não estão contribuindo para mudanças nos índices. Consideramos que aproximar os alunos do modelo do instrumento avaliativo seja pertinente desde que não esteja desconectado com os objetivos de ensino desenvolvidos naquele período (mês, bimestre, etapa, semestre...), porém, não foi esta a realidade compartilhada.

Encerramos este artigo reafirmando que o treino dos alunos não contribui para a elevação de índices de testes padronizados. Enfatizamos que um dos caminhos a ser percorrido, sem perder de vista o objetivo principal - o aprendizado da criança -, é o docente tomar as decisões a partir dos objetivos propostos da rede de ensino, aliadas ao conhecimento do seu aluno e às diferentes fontes avaliativas.

Quando nos reportamos aos diferentes autores que embasaram teoricamente a pesquisa de mestrado (MACHADO, 2017), no sentido de que a avaliação deva promover a aprendizagem, enfatizamos que seja o processo avaliativo, o olhar constante do professor em seu aluno, em seu aprendizado e no objetivo a ser alcançado, que deva ser o fio condutor das ações pedagógicas. Conduzir a ação docente em função de índices de avaliação externa é valorizar unicamente um meio avaliativo, é desconsiderar a função avaliativa do profissional e, se este apresentar dúvidas, precisa e deve ser ajudado.

Villas Boas (2008) nos alerta quanto ao uso dos resultados das avaliações, reforçando que não deve ser utilizada apenas para atribuição de notas. "Precisamos pensar: qual a importância no processo avaliativo? Por que usá-la? Com quais objetivos? Quando usá-la? Como articular seus resultados aos de outros procedimentos?" (VILLAS BOAS, 2008, p. 91). Este mesmo processo reflexivo deve acontecer também na chegada dos índices de desempenho dos alunos à escola. Deve-se, sim, utilizar os resultados como mais uma ferramenta avaliativa, agregar aos outros instrumentos utilizados, trocar reflexões e possibilidades de trabalho, estar atento às necessidades formativas destes docentes e verificar se é sobre avaliação padronizada. 
É preciso tomar cuidado para que a avaliação externa não se torne a "vilã" dentro da escola, na prática docente e acabe por refletir no desenvolvimento de aprendizagem do aluno. Ela é mais um instrumento que, aliado à avaliação da aprendizagem realizada diariamente pelo professor, poderá contribuir para a sinalização de uma maior atenção no desenvolvimento de determinadas habilidades naquele ano escolar.

Alguns docentes podem questionar o fato dos resultados da avaliação externa chegarem às escolas no ano seguinte à realização da prova e, desta forma, não ser mais significativo. É preciso considerar que, apesar de não estar mais com a mesma turma, a chegada dos resultados pode contribuir para um momento de reflexão do profissional, das ações que foram realizadas para a consolidação das habilidades básicas daquelas crianças, naquele determinado ano escolar, e as ações que necessitam serem aprimoradas; refletir sobre o ato avaliativo desenvolvido em sala de aula, seus resultados e compará-los com os resultados externos: em que se assemelham? Em que divergem?

Enfim, é primordial que se utilize os resultados dos diferentes instrumentos avaliativos (seja da avaliação externa ou da aprendizagem) sem perpetuar o papel de vilã da avaliação - nem para os alunos, nem para os docentes. Esta deve subsidiar as decisões dos professores, proporcionando a reflexão da ação docente para a promoção da aprendizagem dos alunos. Como diria Lima (2013, p. 62), "avaliar para intervir e para levar a aprender fará a diferença”, em todas as dimensões e em todos os níveis de avaliação.

\section{REFERÊNCIAS}

BITAR, H.A.F. O Sistema de Avaliação do Rendimento Escolar do Estado de São Paulo: implantação e continuidade. Série Ideias, São Paulo, n. 30, p. 9-20, 1998. Disponível em: http://www.crmariocovas.sp.gov.br/ext_a.php?t=006. Acesso em: 23 mar. 2015.

BONAMINO, A.; SOUSA, S. Z. Três gerações de avaliação básica no Brasil: interfaces com o currículo da/na escola. Revista: Educação e Pesquisa, São Paulo, v. 38, n. 2, p. 373 - 388, abr./jun. 2012. Disponível em: http://www.scielo.br/pdf/ep/v38n2/aopep633.pdf. Acesso em: 10 mar. 2016.

BRASIL. Lei n. 9394, de 20 de dezembro de 1996. Estabelece as diretrizes e bases da educação nacional. Brasília, DF: Presidência da República, 1996. Disponível em: http://www. planalto.gov.br. Acesso em: 05 set. 2015.

. Ministério da Educação. Portaria n. ${ }^{\circ}$ 931, de 21 de março de 2005. Institui o Sistema Nacional de Avaliação da Educação Básica. Diário Oficial da União: seção 1, Brasília, DF, n. ${ }^{\circ}$ 55, p. 17, 22 mar. 2005. Disponível em: http://portal.inep.gov.br/web/guest/educacaobasica/saeb/documentos-e-legislacao. Acesso em: fev. 2017.

. Ministério da Educação. Secretaria da Educação Básica. Instituto Nacional de Estudos e Pesquisas Educacionais Anísio Teixeira. Diretoria de Avaliação de Educação Básica. Plano de Desenvolvimento da Educação/PDE/SAEB/2011. Brasília: MEC, 2011.

. Diretoria de Formação de Professores da Educação Básica. Relatório de Gestão. Brasília, 2013. Disponível em: https://www.capes.gov.br. Acesso em: 25 abr. 2016.

DEPRESBITERIS, L.; TAVARES, M.R. Diversificar é preciso... instrumentos e técnicas de avaliação de aprendizagem. São Paulo: SENAC, 2009.

FUNDAÇÃO VUNESP. SARESP - Sistema de Avaliação do Rendimento Escolar do Estado de São Paulo. Boletim de resultados, 2014. 
INEP. Instituto Nacional de Estudos e Pesquisa Educacionais Anísio Teixeira. Ministério da Educação. SAEB - Sistema de Avaliação da Educação Básica. Disponível em: http://portal. inep.gov.br/web/guest/educacao-basica/saeb. Acesso em: set. 2016.

HAYDT, R. C. C. Curso de Didática geral. São Paulo: Ática, 2011.

HORTA NETO, J. L. Um olhar retrospectivo sobre a avaliação externa no Brasil: das primeiras medições em educação até o SAEB de 2005, Revista Iberoamericana de Educación, v. 42, n. 5, p. 1-14, 2007. Disponível em: http://www.rieoei.org/deloslectores/1533Horta.pdf. Acesso em: 09 abr. 2015.

LIBÂNEO, J.C. Didática. 2. ed. São Paulo: Cortez, 2013.

LIMA, E. S. Avaliação formativa: indutora das aprendizagens de todos na escola. In: Serviço Social da Indústria (São Paulo). Divisão de Educação e Cultura (DEC). Saber em ação 2012. São Paulo: SESI - SP, 2013. p. 51 - 69.

LUCKESI, C. C. Avaliação da aprendizagem escolar. 19. ed. São Paulo: Cortez, 2008.

LUCKESI, C.C. Avaliação da aprendizagem: componentes do ato pedagógico. São Paulo: Cortez, 2011.

MACHADO, K. O Sistema de Avaliação do Rendimento Escolar do Estado de São Paulo (SARESP) e o ensino da língua materna em uma rede particular. 2017. Dissertação (Mestrado em Educação) - Universidade Federal de São Carlos, São Carlos, 2017.

SÃO PAULO. (Estado). Resolução n 27 de 29 de março de 1996. Dispõe sobre o Sistema de Avaliação do Rendimento Escolar do Estado de São Paulo. São Paulo: [s. n.], 1996. Disponível em: http://www.educacao.sp.gov.br. Acesso em: 15 abr. 2016.

Secretaria da Educação. Matrizes de referência para a avaliação SARESP: documento básico. São Paulo: SEE, 2009.

Relatório dos estudos do SARESP/Língua Portuguesa e Matemática $/ 2^{\circ}$ e $3^{\circ}$ ano do ensino fundamental/2013. São Paulo: SEE, 2014a.

SARESP/2013 - Sumário Executivo. v. 1. São Paulo: FDE, 2014b.

Relatório Pedagógico de Língua Portuguesa/2014. São Paulo: SEE, 2014c.

Relatório dos estudos do SARESP/Língua Portuguesa e Matemática/2 ${ }^{\circ}$ e $3^{\circ}$ ano do ensino fundamental/2014. São Paulo: SEE, 2015.

SESI - SP (Serviço Social da Indústria). Fazer Pedagógico: livro do professor/SESI - SP. São Paulo: SESI - SP Editora, 2010.

Referencial Curricular: ensino fundamental. São Paulo: SESI - SP Editora, 2015.

SCHNEUWLY, B.; DOLZ, J. Gêneros orais e escritos na escola. Campinas: Mercado das Letras, 2004.

SOUSA, C. P. Dimensões da avaliação educacional. Estudos em Avaliação Educacional, n. 22, p. 101 - 118, 2000. Disponível em: http://www.fcc.org.br. Acesso em: 16 mar. 2016.

VILLAS BOAS, B. M. F. Virando a escola do avesso por meio da avaliação. 2. ed. Campinas: Papirus, 2008.

VILLAS BOAS, B. M. F. Portfólio, avaliação e trabalho pedagógico. 8. ed. Campinas: Papirus, 2012.

WEISZ, T. O diálogo entre o ensino e a aprendizagem. São Paulo: Ática, 2009. 